standard mathematical representation. In this case information seems to be approximate because usually people assigns a different degree of the certainty depending on circumstances and the context of the data.

\section{The Method of Converting an Expert Opinion to Z-number}

\author{
E.A. Glukhoded < glukhodedkate@gmail.com> \\ S.I.Smetanin <sismetanin@gmail.com> \\ National Research University Higher School of Economics \\ 20, Myasnitskaya st., Moscow, 101000 Russia
}

Abstract. The concept of Z-numbers introduced by Zade in 2011 is discussed topically nowadays due to it aptitude to deal with nonlinearities and uncertainties whose are common in real life. It was a large step of representing fuzzy logic, however that numbers created much larger problems of how to calculate them or aggregate multiple numbers of that type. Z-numbers have a significant potential in the describing of the uncertainty of the human knowledge because both the expert assessment and the Z-number consists of restraint and reliability of the measured value. In this paper, a method of converting an expert opinion to $\mathrm{Z}$-number is proposed according to set of specific questions. In addition, the approach to Znumbers aggregation is introduced. Finally, submitted methods are demonstrated on a real example. The topicality of the research is developing a new algorithm and software (based on that development) which could help people make decision in a messy uncertainty with many parameters and factors that are also defined imprecisely. In this work, we present the research that is aimed to find the most efficient methods to operate them (aggregate, add, divide). Firstly, it is important to identify all existing methods of aggregating Z-numbers. Secondly, it is needed to invent new methods of how work with them. The most interesting techniques should be detailed and summarized. There is also a program that is developed to model the real-word task of decision-making.

Keywords: Z-number, fuzzy measure, aggregation, expert opinion, fuzzy number.

DOI: $10.15514 /$ ISPRAS-2016-28(3)-1

For citation: Glukhoded E.A., Smetanin S.I. The Method of Converting an Expert Opinion to Z-number. Trudy ISP RAN/Proc. ISP RAS, vol. 1, issue 2, 2016. pp. 7-20. DOI: 10.15514/ISPRAS-2016-28(3)-1

\section{Introduction}

Science and engineering tends to deal with different kinds of measures and evaluations, but in fact not all assessment of information can be represented as a clear number. It's common practice for human beings to describe the information in a linguistic terms which are more convenient in everyday life but unsuitable for a
In order to resolve problem of the uncertainty degree representation, Zadeh proposed the concept of Z-numbers in 2011 [1]. According to this concept, Znumber describes an uncertain variable $\mathrm{V}$ as an ordered pair of fuzzy numbers (A, $\mathrm{B})$, where the first number is a fuzzy set of the domain $\mathrm{X}$ of the variable $\mathrm{V}$ and the second one is a fuzzy set that specifies the level of a reliability of the first number as a unit interval.

Fuzzy logic methods are discussed topically last few decades due to its aptitude to deal with nonlinearities and uncertainties whose are common in real life. Despite the widespread application of many methods of fuzzy logic, it seems to be critical to talk about decision appliance without relation to the confidence and the reliability of analysed information especially in the field of fuzzy decision-making. For example, the decision, which was accepted based on low- reliability data, tends to be useless or even harmful on a practice usage. In this case, Z-numbers have a significant potential in describing uncertainty of the human knowledge because both the expert assessment and the Z-number consist

of restraint and reliability of the measured value. In this paper, the method of converting an expert opinion to Z-number is proposed and the new aggregation approach is introduced. At the end, suggested methods are demonstrated.

The paper is organized as follows. In section 2 required preliminaries are presented. In section 3 problem statement is described in details. In section 4 a method of converting expert assessment to Z-numbers is proposed. In addition, the approach to $Z$-numbers aggregation is introduced. In section 5 proposed methods is demonstrated on the real-life example. In the last section the key results of the article is mentioned and further ways of research is suggested.

\section{Preliminaries}

\subsection{A linguistic variable}

A linguistic variable is a variable whose values are linguistic expression such as sentences, phrases or words in an artificial or natural language. Processing data provided in linguistic variables requires the computing in terms of nonlinear approaches and leads to results, which are also not precise as the original data.

In general, the usage of linguistic variables is motivated by the feature that they provide more generalized information in contrast with numeric variables. For example, Speed is a linguistic variable which can be set to 'very slow', 'slow', 'middle', 'quite high', 'high', 'very high', etc. In natural language this linguistic variable may be represented as follows: 'The speed of the car is slow'. In this case, the characteristic of object under observations given in generalized form i.e. without 
any specific numeric values, so expert has no need in specific measuring equipment for object estimation.

\subsection{Fuzzy sets}

Let $X$ be a space of points (objects), with a generic element of $X$ denoted by $x$. Thus, $X=\{x\}$. A fuzzy set [2] (class) $A$ in $X$ is characterized by a membership (characteristic) function $\mu(x)$ which associates with each point in $X$ a real number in the interval $[0,1]$, with the value of $\mu(x)$ at $\mathrm{x}$ representing the 'grade of membership' of $x$ in $A$. Thus, the nearer the value of $\mu(x)$ to unity, the higher the grade of membership of $x$ in $A$. When $\mathrm{A}$ is set in the ordinary sense of term, its membership function can take on only two values 0 and 1 , with $\mu(x)$ reduces to the familiar characteristic function of set A. [17, 18]

In the decision-making tasks [3] each expert gives his own opinion and then it is needed to represent given information in a form that can be processed by a machine. We can use fuzzy numbers for representing the information. Fuzzy numbers can be defined as follows.

\subsection{A fuzzy number}

A fuzzy number $[14,15]$ is a convex and normalized fuzzy set with membership function, which is defined in $\mathrm{R}$ and piecewise continuous. In other words, a fuzzy number represents an interval of crisp numbers with fuzzy boundary.

Classical example of fuzzy number is triangular fuzzy number. It is represented by a set of two boundary points a1 a3 and a peak point a2, i.e. [a1, a2, a3], as shown in Fig. 1.

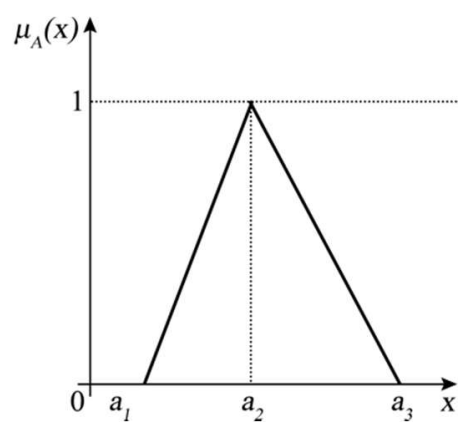

Fig. 1. A triangular fuzzy number

A concept of Z-numbers [8] was proposed in 2010, which was associated with a factor of information reliability for decision-making tasks, a description of the various aspects in the world, an expression of ideas or assessments.

\subsection{A Z-number}

A Z-number [2] is an ordered pair of fuzzy numbers denoted as $Z=(A, R)$. The first component $A$, a restriction on the values, is a real-valued uncertain variable $X$. The second component $\mathrm{R}$ is a measure of reliability for the first component.

\subsection{A Z+-number}

$\mathrm{Z}+$ number [2] is a combination of fuzzy number, A, and a random number, $\mathrm{R}$, written as an ordered paid $\mathrm{Z}+=(\mathrm{A}, \mathrm{R})$. A plays the same role as in a $\mathrm{Z}$-number, $\mathrm{R}$ is a probability distribution of random number.

\section{Problem statement}

Communications between people is often reduced to the expression of their opinions, reviews or evaluations. Some examples of everyday expert assessments are follows:

1. «What is the weather forecast for tomorrow? I really don't know, but I am quite sure that it will be warm». In this example, during the conversation an expert provides an assumption of the prospective weather in linguistic terms and mention a degree of confidence in it. Therefore, $\mathrm{X}=$ Weather forecast for tomorrow, and $\mathrm{Z}=<$ warm, quite sure $>$.

2. «It takes me about 2 weeks to finish course work». Therefore, $X=$ Time to finish course work, and $\mathrm{Z}=<$ about 2 weeks, usually $>$.

Generally, the formalization of the statements in a natural language is a complex and unobvious task $[9,10]$. For example, the degree of confidence or reliability of the expert estimation can be provided in two ways, namely in explicit or implicit form [11]. The explicit form is represented in example (i) in linguistic term 'quite sure' and the implicit form is contained in the context in example (ii).

Now, it is needed to formulate the problem in a general way. Consider, set of objects $(\Omega)$ that needs to be assessed by experts or people who have specific knowledge in the field that relates to $\Omega$. Also, there is set of criteria $(\pitchfork)$, that should be taken into account. In this paper it is not supposed to describe the methods for assessments aggregation. That is why it does not need to involve set of experts in problem statement formulation.

Each expert expresses his own opinion by filling the form with question that are written in a developed form. Questions are formulated using conventional language, such as "how can you assess the level of safety of the given system?" or "Are you sure that the level is high?" or, probably, the most complicated: "How can you assess the distribution of that parameter? Is it Gaussian?" Strict form will be illustrated in the chapter $\mathrm{V}$.

When expert filled his questionnaire with answers it is needed to represent given information in a form that can be processed by machine. There could be several levels of abstraction for representing the information (table 1). 
Table 1. Levels of abstraction [5]

\begin{tabular}{|c|c|c|}
\hline \multirow{2}{*}{ Level } & \multicolumn{2}{|c|}{ Appearance (in Time New Roman or Times) } \\
\cline { 2 - 3 } & \multicolumn{2}{|c|}{ Numbers } \\
\hline 3 & \multicolumn{2}{|c|}{ Z-numbers or Z+-numbers } \\
\hline 2 & Fuzzy numbers & Random numbers \\
\hline 1 & \multicolumn{2}{|c|}{ Intervals } \\
\hline 0 & \multicolumn{2}{|c|}{ Crisp numbers (Integer or Float) } \\
\hline
\end{tabular}

In this paper the highest level supposed to be considered - Z-numbers. Actually, there will be even $\mathrm{Z}+$-numbers in the chapter IV and $\mathrm{V}$.

The main goal of all paper is to describe the recipe of how human-readable information could be represented as Z- numbers. It should be also mentioned that expert's opinions per each criterion should be somehow accumulated (or aggregated) in a common Z-number that will describe whole relation of a criterion to the considered object.

\section{The proposed method of converting an expert opinion to z- \\ number}

First of all, it is needed to describe strict form that expert needs to fill in order to provide knowledge. Form should contain $\mathrm{N}$ sections of $\pitchfork$. Each section should contains several questions that should describe relation of the criterion $\mathrm{C} \in \pitchfork$ to the object $\mathrm{O} \in \Omega$. Common questions are follows:

1. How does O meet C? Specify the level.

2. Do you have an experience with $\mathrm{O}$ ? How wide was it?

3. Have you taken into account $\mathrm{C}$ when using $\mathrm{O}$ previously? (If have any experience)

4. Do you follow the latest information about $\mathrm{O}$ ? When was the latest update?

5. (Only if experts said 'yes' on second question) Which distribution, you think, respects to people perception of $\mathrm{C}$ when talking about $\mathrm{O}$ ?

First and fourth questions are related to the main part of Z- number, other questions are somehow related to the measure of reliability for the first component. Let us begin with the main part of Z-number. First question is direct. It is supposed that expert assesses the level of affection $\mathrm{C}$ on $\mathrm{O}$ in the following terms: very high $(8,9$, $10)$, high $(7,8,9)$, medium $(5,6,7)$, low $(3,4,5)$, very low $(1,2,3)$, does not meet at all $(0,1,2)$. However, it would be incorrect to assign fuzzy numbers to each option before he answered fourth question. This question would show how precise expert could be answering previous one. For example, if he says that he does not follow information for a long time, it should be a clear sign that bounds of each triangle (or trapezoidal) fuzzy-numbers should be widened due to some incompetency in the given field. According to that, there could be different fuzzy numbers for medium: $(4,5,6)$ or $(2,5,8)$.

The formation of second part should be following. Possible answers for question two are: wide experience, have experience, some experience, little experience, no experience. All these statements could be represented as fuzzy number: $(0.8,0.9$, $1.0),(0.65,0.75,0.85),(0.4,0.5,0.6),(0.1,0.3,0.4),(0,0.1,0.2)$. Answers for the question three could be: yes, a lot $(0.8,0.9,1.0)$; yes, sometimes $(0.5,0.6,0.7)$; yes, a little $(0.2,0.3,0.4)$; no $(0.0,0.1,0.2)$. Fifth question is auxiliary and will not be converted into fuzzy number. It relates to $\mathrm{Z}+-$ numbers. Possible answers: Gaussian, Inverse Gaussian, Binomial, Gamma. It is not prohibited for an expert to skip this question. However, if expert answers the question the specific 'confidentiality' fuzzy number has a value of $(0.6,0.7,0.8)$ - 'high', otherwise - $(0.0,0.1,0.2)-$ 'low'.

Then several rules should be formulated to construct possibility measure of Znumber: IF experience='wide' AND take-in-account='a lot' AND confidentiality='high' THEN measure='very high'.

Table 2 is completed according to the given format.

Table 2. Rules for probability measure

\begin{tabular}{|c|c|c|c|c|}
\hline \multirow{2}{*}{$\#$} & \multicolumn{3}{|c|}{ CONDITION } & RESULT \\
\cline { 2 - 5 } & Exper. & Take-in & Conf. & Measure \\
\hline 1 & Wide & A lot & High & Very high \\
\hline 2 & Wide & A lot & Low & High \\
\hline 3 & Wide & Sometimes & High & Very high \\
\hline 4 & Wide & Sometimes & Low & High \\
\hline 5 & Wide & A little & High & High \\
\hline 6 & Wide & A little & Low & Medium \\
\hline 7 & Wide & No & High & High \\
\hline 8 & Wide & No & Low & Medium \\
\hline 9 & Have & A lot & High & Very high \\
\hline 10 & Have & A lot & Low & High \\
\hline 11 & Have & Sometimes & High & High \\
\hline 12 & Have & Sometimes & Low & Medium \\
\hline 13 & Have & A little & High & High \\
\hline 14 & Have & A little & Low & Medium \\
\hline 15 & Have & No & High & Medium \\
\hline 16 & Have & No & Low & Low \\
\hline 17 & Some & A lot & High & High \\
\hline 18 & Some & A lot & Low & Medium \\
\hline 19 & Some & Sometimes & High & Medium \\
\hline 20 & Some & Sometimes & Low & Medium \\
\hline 21 & Some & A little & High & Medium \\
\hline 22 & Some & A little & Low & Low \\
\hline
\end{tabular}


Глуходед Е.А.,, Сметанин С.И. Метод представления мнений экспертов в виде Z-чисел. Труды ИСП РАН, том 28 , вып. 3, с. 7-20

\begin{tabular}{|l|c|c|c|c|}
\hline \hline 23 & Some & No & High & Medium \\
\hline 24 & Some & No & Low & Low \\
\hline 25 & Little & A lot & High & Medium \\
\hline 26 & Little & A lot & Low & Low \\
\hline 27 & Little & Sometimes & High & Medium \\
\hline 28 & Little & Sometimes & Low & Low \\
\hline 29 & Little & A little & High & Low \\
\hline 30 & Little & A little & Low & Low \\
\hline 31 & Little & No & High & Low \\
\hline 32 & Little & No & Low & Very low \\
\hline 33 & No & - & - & Very low \\
\hline
\end{tabular}

Then, after the result is given, it should be converted to fuzzy number:

- Very high $-(0.8,0.9,1.0)$

- $\quad$ High - $(0.6,0.7,0.8)$

- Medium - $(0.4,0.5,0.6)$

- $\quad$ Low $-(0.2,0.3,0.4)$

- Very low - $(0.0,0.1,0.2)$

- The B-part is given.

The resulting $Z$-number should be constructed from both parts $Z$ (A, B).

Then, it is time to aggregate different $Z$-numbers into one Z-number which can describe whole relation of $\mathrm{O}$ to the subject according to $\mathrm{C}$ based on expert's opinion. There are, a least, three methods of aggregation:

1. Converting Z-number into simple fuzzy number and aggregate them using simple methods $[4,12,13]$.

2. Aggregating A and B-part separately $[14,18]$.

3. Converting $Z$-number into $Z+$ +number, aggregating $Z+$-numbers and then convert given $\mathrm{Z}+$-number into $Z$-number [6, 7].

First approach is the simplest one, but lose some information from an expert. Third approach is one where loss of information is minimized, but it is complicated and it would be difficult to provide all calculations in this paper (requires some non-linear optimization algorithms at some stages). That is why second approach is chosen.

At first stage, it is needed to aggregate A-parts $[17,18]$ :

$$
\widetilde{w}=\left(a_{r}, b_{r}, c_{r}\right)
$$

Here $a_{r}=\min \left(a_{i}\right), b_{r}=\frac{1}{n} \sum_{i=1}^{n} b_{i}, c_{r}=\max \left(c_{i}\right), \mathrm{N}$ - total number of Z-numbers (1)

Aggregation of B-parts are more complicated. First of all, it is needed to multiply one number on another.
IE.A.Glukhoded, S.I.Smetanin. The Method of Converting an Expert Opinion to Z-number. Trudy ISP RAN/Proc. ISP RAS, 2016, vol. 28, issue 3, pp. 7-20.

$$
\mu(z)=\left\{\begin{array}{l}
\frac{\left.-a_{1} b_{2}+a_{2} b_{1}-2 a_{1} a_{2}\right)+\sqrt{\left(a_{1} b_{2}-a_{2} b_{1}\right)^{2}+4\left(b_{1}-c_{1}\right)\left(b_{2}-a_{2}\right) z}}{2\left(b_{1}-a_{1}\right)\left(b_{2}-a_{2}\right)}, a_{1} a_{2} \leq z \leq b_{1} b_{2} \\
\frac{\left.-c_{1} b_{2}+c_{2} b_{1}-2 c_{1} c_{2}\right)+\sqrt{\left(c_{1} b_{2}-c_{2} b_{1}\right)^{2}+4\left(b_{1}-c_{1}\right)\left(b_{2}-c_{2}\right) z}}{2\left(b_{1}-c_{1}\right)\left(b_{2}-c_{2}\right)}, b_{1} b_{2} \leq z \leq c_{1} c_{2} \\
0, \text { otherwise }
\end{array}\right.
$$

Second stage of aggregation assumes that square root calculations should be applied to the given fuzzy number. Somehow, these transformations could be compared with a calculation of geometric mean, when talking about crisp numbers.

$$
\mu_{\sqrt{x}}(x)=\left\{\begin{array}{cl}
\frac{x^{2}-a}{b-a}, & \sqrt{a} \leq x \leq \sqrt{b} \\
\frac{c-x^{2}}{c-b}, & x \sqrt{b} \leq x \leq \sqrt{c} \\
0, & \text { otherwise }
\end{array}\right.
$$

The resulting fuzzy number is aggregated B-part.

\section{A numerical example}

Consider following example. It is needed to decide whether it is important to have a new developer in a company or not. To decide more accurately, management of software company introduces a research. Several 'experts' are chosen from different departments. Now, focus on a specialist of marketing. His assessment should be transformed into Z-number for further calculations. It is not necessary for that time to come to a complete conclusion, just focus on how expert's evaluation lead to obtaining Z-number.

\subsection{Filling a form}

There is a strict form with several questions and two criteria.

Questions for the $1^{\text {st }}$ criterion - level of business in the department:

1. How do you think, does the department of software development are filled with work? (very much, much, probably, not so much, no, not at all)

2. How often do you communicate with developers during business tasks? Select from: very often, often, quite often, rarely, not communicate.

3. Did you notice anytime, that deadline was broken due to lack of programmers? Do you pay attention on it? Select from: Notice very often, sometimes notice, I've noticed once, Not at all.

4. Did you follow the news of our developers' team? Do you know most of them? Select from: Yes, communicating each day; Yes, communicating several times a week; Yes, but communicating rarely; No, I'm not.

5. Which distribution, you think, respects to people perception of lack of human resources when talking about new coming developer? (Only if you know)

Questions for the $2^{\text {nd }}$ criterion - company's resources: 
1. How do you think, does the company have enough resource to hire new employee(s) in a software department? Select from: More than enough; enough; quite enough; probably, not enough; not enough at all.

2. Have you ever been interested in our company's revenue, stock prices etc.? Select from: Yes, I follow all news; yes, sometimes; yes, but rarely; probably, once; no.

3. Have you ever thought about how newcomers can change our budget or resources distribution? How you thought about it when you came? Select from: Yes, thought a lot; yes, sometimes; yes, when I came; No.

4. Do you follow latest news about our state, about our resources distribution on different projects? Select from: Yes, always; yes, sometimes; yes, but rarely; no, I'm not.

5. Which statistics distribution, you think, respects to people perception of our resources when talking about new employees? (Only if you know)

The marketing expert gives answers:

Criterion 1:

1. Not so much

2. Rarely

3. Sometimes notice

4. No, I'm not

5. -

Criterion 2:

1. Quite enough

2. Yes, I follow all news

3. Yes, sometimes

4. Yes, sometimes

5.

\subsection{Constructing Z-numbers}

According to calculations in section 4 and table 2 it is possible to calculate two Znumbers from his answers.

Z-number from the $1^{\text {st }}$ criterion: $\{(1,4,7),(0.2,0.3,0.4)\}$

$Z$-number from the $2^{\text {nd }}$ criterion: $\{(5,6,7),(0.6,0.7,0.8)\}$

Second part of Z-numbers is given by applying corresponding rules from Table II.

\subsection{Aggregating Z-numbers}

A-part of Z-numbers is aggregated simply by applying formula (1) from section 4 The resulting A-part: $(1,5,7)$
IE.A.Glukhoded, S.I.Smetanin. The Method of Converting an Expert Opinion to Z-number. Trudy ISP RAN/Proc. ISP RAS, 2016, vol. 28, issue 3, pp. 7-20

B-part of Z-numbers is calculated using formula (2) and (3) from section 4. For simplicity, all calculations would not be provided, only bounds for each of fuzzy number at every step. After multiplication following fuzzy number is obtained:

$$
B_{m}=(0.12,0.21,0.32)
$$

Then, after applying square root transformation:

$$
B_{r} \approx(0.35,0.46,0.57)
$$$$
B_{r}-\text { resultin } B-\text { par of } Z-\text { number }
$$

It should be noticed, that bounds are not lines in this case, they are quadratic functions.

That is why, the resulting Z-number looks as follows:

$$
Z_{r}=\{(1,5,7),(0.35,0.46,0.57)\}
$$

This Z-number expresses overall relation to the problem of marketing expert. It could be translated to the normal language such as: "he doubts that software department needs new employee and probably, they do not need, but he is not sure enough"

\section{Conclusion}

Consider following example. It is needed to decide whether it is important to have a As a result of this research, a method of converting an expert opinion to Z-number was proposed. The key problems of Z-number extraction from natural language statements were discussed and an example illustrating the supposed algorithm were provided. In addition, the new method of $Z$-numbers aggregation was proposed and demonstrated on the real example.

The further research will be aimed on improving methods of aggregation in order to obtain a more accurate and reasonable result at the output. The high-quality processing of experts assessments allows the use of this approach in the real world in order to solve complex problems not only in the business sector, but also in the everyday life. The next step is developing an approach to perform arithmetic operations with observed Z-numbers. Only after successful finishing of these steps, a complete system for $Z$-numbers processing could be built.

\section{References}

1]. Adrian K. Rantilla, David V. Budescu. Aggregation of Expert Opinions. In Systems Sciences, HICSS-32. Proceedings of the 32nd Annual Hawaii International Conference, 1999.

[2]. Aliev, R. A., Alizadeh A. V. and Huseynov O. H. The arithmetic of discrete Z-numbers, Inform. Sciences, 290(1), 2015, pp.134-155.

[3]. Aliev, R.A., Alizadeh, A.V, Huseynov, O. H, Aliyev, R.R. The arithmetic of Z-numbers. Theory and Applications. World Scientific, 2015.

[4]. Aliev, R.A., Zeinalova, L. M. Decision-making under Z-information. In Human-centric decision-making models for social sciences, Springer-Verlag,, 2013, pp. 233-252. 
[5]. Bai, Y., Wang, D. Fundamentals of Fuzzy Logic Control - Fuzzy Sets, Fuzzy Rules and Defuzzifications. In Advanced Fuzzy Logic Technologies in Industrial Applications, Springer, 2006 pp. 17-36.

[6]. Detyniecki, M. Fundamentals on Aggregation Operators. Berkeley initiative in Soft Computing, Computer Science Division, University of California, Berkeley, United Sates of America, 2001

[7]. Eiichiro Takahagi. Usage: Choauet integral. Fuzzy Integral Calculation Site (online publication). Available at: http://www.isc.senshuu.ac.jp/ thc0456/Efuzzyweb/mant1/mant1.html, accessed 03.04.2016.

[8]. Farina, M., and Amato, P. A fuzzy definition of "optimality" for many criteria optimization problems. IEEE T. Syst. Man Cy. A: Systems and Humans, 34(3), 2004, pp. 315-326.

[9]. Gilboa I., Schmeidler D. Additive Representations of Non-Additive Measures and the Choquet Integral. Kellogg School of Management, Northwestern University, Center for Mathematical Studies in Economics and Management Science, Discussion Papers (online publication).

Available https://www.kellogg.northwestern.edu/research/math/papers/985.pdf 17.05 .2016

[10]. Gilboa, I. Theory of Decision under Uncertainty. Cambridge University Press, Cambridge, 2009.

[11]. Kang B., Wei D., Li Y., Deng Y. Decision Making Using Z-numbers under Uncertain Environment. Journal of Information \& Computational Science, №8(7), 2012, pp. 28072814

[12]. Kang, B., Wei, D., Li, Y., Deng, Y. A method of converting Z-number to classical fuzzy number. Journal of Information \& Computational Science, №9(3), 2012 pp. 703-709.

[13]. Lala M. Zeinalova, Choquet aggregation based decision making under Z-information. ICTACT Journal on Soft Computing, 4(4), 2014, pp. 819-824.

[14]. Studies in Fuzziness and Soft Computing, vol. 97. Tomasa Calvo, Gaspar Mayor, Radko Mesiar (eds). Aggregation Operators. New Trends and Aplications. Physica-Verlag Heidelberg, 2002, $352 \mathrm{p}$

[15]. Zadeh, L.A. A Note on Z-numbers. Information Sciences, №181, pp. 2923-2932.

[16]. Zadeh, L.A. Fuzzy sets. Information and Control, vol. 8(3), pp. 338-353, 1965.

[17]. Gulnara Yakh'yaeva. [Fundamentals of the theory of fuzzy sets. Lecture 4. Indicator for fuzziness of fuzzy sets. Fuzzy measures and integrals] (online publication). Available at: $\mathrm{http}: / /$ www.intuit.ru/studies/courses/87/87/lecture/20505?page $=3$, accessed 15.05 .2016 (in Russian).

[18]. Sakulin S.A., Alfimtsev A.N. On the issue of the practical application of fuzzy measures and Choquet integral. Herald of the Bauman Moscow State Technical University. Series Instrument Engineering, spec. issue 4: Computer Systems and Technologies, 2012, pp. 55-63 (in Russian).
Метод представления мнений экспертов в виде Z-чисел

Глуходед E.A $<$ glukhodedkate@gmail.com $>$

Сметанин С.И. <sismetanin@gmail.com>

Научно-исследовательский университет Высшая школа экономики

101000, Россия, г. Москва, ул. Мясничкая, д. 20

Аннотация. Нечеткие числа используются в задачах моделирования для учета лингвистической неопределенности. Большинство информации, обрабатываемой в различных сферах деятельности, основано на оценках, которые не всегда могут быть выражены точным числом. Как правило, используются привычные для человека слова или выражения естественного языка. Надежность и достоверность данных, которые мы получаем для решения тех или иных задач играет важную роль. Мы часто работаем с неполной информацией, основанной на опыте и оценках различных экспертов Поэтому возможность формализации данных такого типа и выполнения с ними различных вычислений помогает более точно решать задачи по планированию принятию решений, оценке рисков и других аспектов практической деятельности. В 2010 году профессор Лотфи Заде предложил концепцию $Z$-чисел, которая связана с фактором надежности используемой информации (при принятии решений, при описании различных аспектов окружающего мира, при выражении идей или суждений людьми). $Z$-число описывает значение некоторой неопределённой переменной $X$ и представляет собой упорядоченную пару из двух нечетких чисел $Z=(A, B)$. Первое из которых (A) выражает ограничение на возможные (вероятные) значения рассматриваемой в конкретном приложении переменной $X$. Второе число $(B)$ есть мера (оценка) уверенности в том, что $A$ именно такова, как она представлена. Числа $A$ и $B$ часто описываются фразами естественного языка, например, $Z=$ (Java, максимально уверен). В данном случае переменная $X=$ «язык программирования для решения определенной задачи», следовательно, утверждение « $X$ является Јаvа» оценивается как надежное ( $B=$ “максимально уверен”). Данная концепция имеет большой потенциал стать важным инструментом в решении различного рода задач, связанных с неполнотой и неточностью описания используемой информации. Вторым основным аспектом данной работы является агрегация информации, а именно $Z$-чисел. Агрегация (англ. aggregation) - основной этап для решения задач по принятию решений. Как правило, чтобы прийти к определенному выводу, необходимо проанализировать несколько источников и объединить полученную информацию. В настоящее время большинство задач по принятию решений имеют множество факторов, определенных нечетко и поэтому решаются интуитивно. Агрегация данных, представленных в нечетком виде, а именно Z-числами, может оказать поддержку в решении задач такого рода. Данная работа представляет собой исследование, связанное с разработкой и изучением эффективных методов обработки $Z$-чисел и выполнения операций над ними.

Ключевые слова: Z-число, нечеткая мера, агрегация, мнения экспертов, нечеткое число.

DOI: $10.15514 /$ ISPRAS-2016-28(3)-1 

мер и интеграла Шоке. Вестник МГТУ им. Н. Э. Баумана. Сер. Приборостроение, спец. вып. 4: Компьютерные системы и технологии, стр. 55-63, 2012.

\section{Список литературы}

[1]. Adrian K. Rantilla, David V. Budescu. Aggregation of Expert Opinions. n Systems Sciences, HICSS-32. Proceedings of the 32nd Annual Hawaii International Conference, 1999.

[2]. Aliev, R. A., Alizadeh A. V. and Huseynov O. H. The arithmetic of discrete Z-numbers, Inform. Sciences, 290(1), 2015, pp.134-155.

[3]. Aliev, R.A., Alizadeh, A.V, Huseynov, O. H, Aliyev, R.R. The arithmetic of Z-numbers. Theory and Applications. World Scientific, 2015.

[4]. Aliev, R.A., Zeinalova, L. M. Decision-making under Z-information. In Human-centric decision-making models for social sciences, Springer-Verlag, 2013, pp. 233-252.

[5]. Bai, Y., Wang, D. Fundamentals of Fuzzy Logic Control - Fuzzy Sets, Fuzzy Rules and Defuzzifications. In Advanced Fuzzy Logic Technologies in Industrial Applications, Springer, 2006, pp. 17-36.

[6]. Detyniecki, M. Fundamentals on Aggregation Operators. Berkeley initiative in Soft Computing, Computer Science Division, University of California, Berkeley, United Sates of America, 2001.

[7]. Eiichiro Takahagi. Usage: Choauet integral. Fuzzy Integral Calculation Site (online) Доступно по ссылке: http://www.isc.senshuu.ac.jp/ thc0456/Efuzzyweb/mant1/mant1.html, 03 апреля 2016.

[8]. Farina, M., and Amato, P. A fuzzy definition of "optimality" for many criteria optimization problems. IEEE T. Syst. Man Cy. A: Systems and Humans, 34(3), 2004, pp. 315-326.

[9]. Gilboa I., Schmeidler D. Additive Representations of Non-Additive Measures and the Choquet Integral. Kellogg School of Management, Northwestern University, Center for Mathematical Studies in Economics and Management Science, Discussion Papers (online), №985, $1992 . \quad$ Доступно по ссылке: $\begin{array}{llll}\text { (online), №985, } & \text { Доступно по2. } & \text { по ссыло } \\ \text { https://www.kellogg.northwestern.edu/research/math/papers/985.pdf, } 17 \text { мая } 2016 .\end{array}$

[10]. Gilboa, I. Theory of Decision under Uncertainty. Cambridge University Press, Cambridge, 2009.

[11]. Kang B., Wei D., Li Y., Deng Y. Decision Making Using Z-numbers under Uncertain Environment. Journal of Information \& Computational Science, № 8(7), , 2012, pp. Environment-2814.

[12]. Kang, B., Wei, D., Li, Y., Deng, Y. A method of converting Z-number to classical fuzzy number. Journal of Information \& Computational Science, № 9(3), 2012, pp. 703-709.

[13]. Lala M. Zeinalova, Choquet aggregation based decision making under Z-information ICTACT Journal on Soft Computing, 4(4), pp. 819-824, 2014.

[14]. Studies in Fuzziness and Soft Computing, vol. 97. Tomasa Calvo, Gaspar Mayor, Radko Mesiar (eds). Aggregation Operators. New Trends and Aplications. Physica-Verlag Heidelberg, 2002, $352 \mathrm{p}$.

[15]. Zadeh, L.A. A Note on Z-numbers. Information Sciences, №181, pp. 2923-2932.

[16]. Zadeh, L.A. Fuzzy sets. Information and Control, vol. 8(3), pp. 338-353, 1965.

[17]. Гульнара Яхъяева. Основы теории нечетких множеств. Лекция 4. Показатель размытости нечетких множеств. Нечеткие меры и интегралы (online). Доступно по ссылке: http://www.intuit.ru/studies/courses/87/87/lecture/20505?page=3, 15 мая 2016. 